from 0 to 4 , it was found that the average degrees of protection for groups of fifteen animals were 0.6 for the negative controls and $1.4,2.4$, and 3.9 for the groups receiving $0.75,1.5$, and 3.0 c.c. orange juice respectively. The relationship between dose and degree of protection is thus linear. In the case of vitamin $\mathrm{D}$, as already stated, the linear relationship held between degree of healing and the logarithm of the dose. The authors found the response of individual guinea-pigs to be very variable. Consistent results could be obtained, however, when groups of five on each dose were employed. The method has the advantages of speed and of giving more precise results than that involving the determination of the mimimum protective dose. The curve obtained can be employed as a standard of reference for the assay of materials containing vitamin $\mathrm{C}$.

For the assay of vitamin A, which is usually tested by its growth-promoting power, a curve relating growth rate to dose given is required. It is possible that other methods may be developed in the future; for example, Coward has found that the number of rats dying when given small doses of the vitamin after a preliminary depletion period, during the second to fifth weeks of vitamin administration, is proportional to the dose given. The same observer has also published curves relating growth rate to dose of vitamin, from which it is possible to determine the potency of an unknown preparation in terms of a selected standard. 3

It was found that the type of casein used in these tests played an essential part. A quantitative relationship between dose and growth was not obtainable when the casein used had first been heated. The synthetic diet was therefore prepared from 'light white casein', dextrinised rice starch, dried yeast, and a salt mixture. Small doses of vitamin D were given weekly or the diet was irradiated. The young rats were given this diet until they ceased to grow. They were then divided into groups, to each of which the same dose of cod liver oil was given daily by hand for five weeks. With doses ranging from $1 \mathrm{mgm}$. to $7.5 \mathrm{mgm}$. daily, the average growth rates varied from $2.0 \mathrm{gm}$. to $10.0 \mathrm{gm}$. per week for this period. The curve obtained by plotting growth against dose given was logarithmic in type : a simple formula could be fitted to it. It was later found that it could be resolved into two similar curves, one for the bucks and one for the does, the formulæ for which are

$$
y=11 \cdot 3+50 \cdot 3 \log x \text { (bucks) and } y=12 \cdot 4+27 \cdot 4 \log x \text { (does) }
$$

where $y$ is mean increase in weight of group in five weeks and $x$ is dose of cod liver oil in milligrams.
Analysis of the results showed that with five rats per dose the error is usually within fifty per cent; with ten, within thirty-three per cent; and with twenty, within three per cent. No seasonal variation in response was noted. The curve is used as a standard of reference in the assay of preparations of vitamin A : the growth responses to several doses of the latter are determined on groups of ten rats each and from the curve the doses of the standard cod liver oil which would have given such responses read off : the potency is proportional to the ratio of the dose of standard to that of the unknown at each level.

The necessity for an accurate biological test for vitamin $A$ has been emphasised by some recent work on the possible chemical and physical characteristics of these vitamins. ${ }^{4}$ It has been generally supposed that the blue colour given by an oil containing vitamin A with antimony trichloride is a good indication of its growth-promoting potency. The investigations of the above authors have now demonstrated that in cod liver oil at least two substances giving a blue colour are present. Comparative biological, chemical, and physical tests of a series of cod liver oils showed that the best agreement with the biological method was given by the measurement of the ultra-violet absorption band (at $3280 \mathrm{~A}$.) of the oil itself, and also by that of the blue value of the unsaponifiable fraction of the oil. Less good agreement was obtained with the measurement of the intensities of the two bands present in the blue colour produced with antimony trichloride, while the least good agreement was shown by the measurement of the blue values of the oils themselves. In other experiments it has been shown that the intensity of the band at $5720 \mathrm{~A}$. in the antimony trichloride test runs parallel with that of the band at $3280 \mathrm{~A}$. in the oil. The intensity of the absorption at $6060 \mathrm{~A}$. in the colour test shows no such relationship. This band appears to be due to the presence of another chromogen ; its intensity is low in fresh oils but can be considerably increased by oxida. tion. It appears, therefore, that until the chemistry of vitamin $A$ has been further elucidated, the final resort for its quantitative estimation must still be the biological test.

1 "The Quantitative Estimation of Vitamin D by Radiography" by R. B. Bourdillon, H. M. Bruce, C. Fischmann, and T. A. Webster. Medical Research Council: Special Report Series, No. 158. Pp $46+2$ plates. (London : H.M. Stationery Office, 1931.) 1s. net.

Biochem.J., vol. 25 , p. $888 ; 1931$.

K. H. Coward, K. M. Key, F. J. Dyer, and B. G. E. Morgan : ibid., vol. 24, p. $1952 ; 1930$ : vol. 25 , p. $551 ; 1931$

- K. H. Coward, F. J. Dyer, R. A. Morton, and J. H. Gaddurn: ibid. vol. 25, p. 1102 ; J. A. Lovern and R. A. Morton: ibid., pp. 1336 and 1341 (with R. H. Creed) ; A. E. Gillam and R. A. Morton: ibid., p. 1346 I. M. Heilbron, A. E. Gillam, and R. A. Morton: ibid., p. 1352.

\title{
Climate of Southern Rhodesia *
}

THE meteorological service of Southern Rhodesia 1 is, of course, in its infancy. Nevertheless, for the period under review 46 climatological stations and 550 rainfall stations were available, a network sufficient to give a good idea of the course of the weather. For the purpose of obtaining a general survey of the rainfall, the element which is of para. mount economic importance to agriculture in such a region, the Report states that a gauge to each 120 square miles is sufficient. Southern Rhodesia contains about 1200 such squares, and of these, 322 are at present occupied by gauges. Just as in the case of the British Isles, the rainfall observers are

- Southern Rhodesia. Meteorological Report for the year ended June 30, 1930, by the Department of Agriculture. Pp. 94. (Salisbury.) practically all voluntary helpers in meteorological work.

Rhodesia is one of those countries where the figure representing the average rainfall of any part for a long period of years is in itself a very uncertain guide as to the suitability of that region for particular branches of agriculture. The principal reason for this is the great variability from year to year of the fall in any part of the rainy season, but to this must be added the fact that much of the rain is received in violent storms-often accompanied by thunderand the rain, even when of reasonable amount as judged by weekly or monthly totals, may be to a great extent lost to agriculture through the rapidity of its ' run-off'. Some striking examples of abnormal 
rainfall are given in this Report: for example, 2.05 inches in fifteen minutes at Riversdale (Charter) on March 7, 1930, and 6.50 inches in one hour at Lundi (Chibi) on Jan. 18, 1930. The latter figure represents very nearly the normal total for the wettest quarter of the year in London. It is natural that every effort should be made to forecast the amount of rain to be expected in each rainy season, and for this purpose it appears that a trial is being made of an equation connecting the general rainfall of Southern Rhodesia with the Nile Flood, pressure at Rio Janeiro, temperature at Mauritius, and minimum temperature at Bulawayo. The necessary values of the independent variables are not available until early in December ; they give a combined correlation coefficient of +0.77 only, which is rather low for forecasting purposes. For the season 1928-29 the forecast departure from normal was -1.2 inches, and the actual departure -1.9 inches. This matter is in the experimental stage, and consequently the forecast was not made public.

The Report contains a good deal of statistical matter relating to the period under review, most of which is in tabular form. There are excellent rain- fall maps, giving the geographical distribution of the year's total and of the normal year's total, both of which illustrate the general tendency for rainfall to decrease with distance from the Indian Ocean. This is a well-recognised feature of most of British South Africa, due to the fact that, apart from local convectional storms in the spring and occasional rains due to tropical hurricanes out on the ocean in late summer or autumn, much of the season's fall is due to dynamical cooling of the south-east trades as they rise over the elevated plateau of South Africa, which winds naturally lose much of their moisture in this way as they penetrate into the interior. Climatic investigation is being extended into the upper atmosphere by means of observations of wind with the aid of pilot balloons liberated at Salisbury. Some of these were followed to a height of ten kilometres. At the higher levels, the predominance of easterly and south-easterly winds appears to be lost, both in summer and winter, at ten kilometres, the directions most favoured in 1929-30 being west and north-west. Since this work was only begun in October 1928, this is the first full year's observations of upper winds.

E. V. N.

\section{Glasgow Meeting of the Chemical Society}

$\mathrm{H}$

OLDING its annual general meeting at Glasgow on March 17, the Chemical Society paid its first visit to Scotland. The choice was particularly appropriate in view of the association both of the president, Prof. G. G. Henderson, and of the Society's first president, Thomas Graham, with that city; moreover, as Sir Thomas Kelly said at the civic reception, the Corporation has a particular interest in chemistry, for they themselves are chemical manufacturers on a very large scale.

In his presidential address, Prof. G. G. Henderson dealt with a matter of pressing importance to all societies which essay to publish the results of scientific investigation, and one which at the present time occasions acute anxiety to those organisations which are nobly attempting to continue to finance an adequate service of abstract publications out of the subscriptions of their members. The burden has fallen very heavily on the Chemical Society. The chief work for which it exists has grown very considerably during the past year; the number of original communications published in the Journal is 24 per cent higher then in 1930, and the number of chemical papers abstracted by the Bureau and published in British Chemical Abstracts "A " is also very much greater than in the previous year. The consequent financial burden is too great for the Society, with its present income, to bear, and at no other period in its long history has the Society been faced with such great difficulties in carrying on its work.

It is, and always has been, the function of the Chemical Society to encourage the development of chemical science in all branches and to provide a regular and complete record of all new additions to chemical knowledge ; nevertheless, it was the Society of Chemical Industry, inaugurated in 1881, which gave to technological chemistry the stimulus then lacking owing to the restricted resources of the older Society, and afterwards the development of other branches of the science has been fostered by the creation of specialist societies. "Looking back on what has happened since 1841," said Prof. Henderson, "the thought arises that if those of our predecessors who managed the affairs of the Chemical Society during the first forty years of its existence had taken a broader and a longer view, some at least of the various societies to which I have referred might not have been founded, and we might now have one great chemical society, with a membership of 10,000 or more, with the members organised into divisions dealing with the different branches of chemistry and possessing a large measure of autonomy. . . ."

Possibly the suggestion that an endeavour should be made to bring about the merging into one organisation of all the various societies concerned with chemistry might be considered impracticable, but Prof. Henderson urged that no effort should be spared to promote the closest possible co-operation between them; so far as the Chemical Society and the Society of Chemical Industry are concerned, a very good case can be made out for reunion. Such a union would almost indubitably effect economies, and the proposal ipso facto merits consideration. Even if the difficulties which stand in the way of bringing about a complete fusion of interests prove to be too great, it should be as possible as it is desirable to arrange for a working partnership of the most intimate character.

An important step in that direction was taken in 1923, when the Bureau of Chemical Abstracts-a joint committee of the two societies responsible for the production and publication of British Chemical $A b$ stracts "A" and "B "-was formed. Upon these two societies alone falls the financial burden of this great work, a task which is performed for the benefit of every chemist in the country. Prof. Henderson pointed out that it is singular and anomalous that there are hundreds, perhaps even thousands, of professional chemists in Great Britain who make no contribution to this burden, who do nothing to help the cause of chemistry in the way that is most urgent, most necessary, and most expensive. He appealed to all chemists to support one or both of the two Societies, even though the Journals may be consulted by non-members in the general and departmental libraries of practically all universitios and colleges, in the libraries of many chemical works and scientific societies, and in a number of public libraries; and even though they rightly find it desirable to subscribe to professional organisations such as the Institute of Chemistry and the British Association of Chemists. 